\title{
ICT Curriculum Transformation of Mathematics in Primary Schools
}

\author{
Christopher K.H. Chin \\ Australian Maritime \\ College
}

\author{
Andrew Fluck \\ University of Tasmania
}

\author{
Dev Ranmuthugala \\ Australian Maritime College
}

\author{
Irene Penesis \\ Australian Maritime \\ College
}

\begin{abstract}
Integral calculus is often taught in high schools to students aged fifteen or older. The project described in this paper investigates the possibility of introducing these concepts and capabilities to students aged 10 to 12 years using computer based algebra system software. At the end of the programme, the students attempt a test based on first year engineering degree calculus examinations. The results clearly show that properly structured programmes utilising appropriate technology can impart the required knowledge and skills to students, even at ages below the target range. In addition, the paper compares the performance of students in four Australian states in their understanding and skill in the handling of the more complicated application questions, with a trend indicating that students from urban schools are outperforming their peers in rural schools. Females also demonstrated better skills at solving real world problems contrary to published data.
\end{abstract}

\section{Introduction}

Computers have become an integral part of our lives in the past decade. Children as young as four years of age are able to use the computer and in primary schools, most students would have access to a computer provided either by the school or their parents.

With Australia heading towards curriculum renewal, there is also a critical shortage of mathematics graduates capable of teaching mathematics in the primary and secondary schools. In particular, there are less than half as many women as men with postgraduate qualifications in Mathematical Sciences [1], which is significant as the majority of primary school teachers in Australia are women. Improving the uptake of mathematics by all students, and women in particular is therefore an important national aspiration.

Hyde, et al [2] suggested that between grades two and 11, the general population no longer shows a gender difference in mathematics skills. However, there is evidence of slightly greater variance in scores for males. Hyde and Mertz [3] showed that in the United States of America, the girls now perform as well as boys in all grades. They add that the gender gap has been closing over time at all levels and will continue to narrow in the future. Nosek, et al [4] identified no overall difference in mathematics achievement between the genders in the 2003 Trends in International Mathematics and Science Study (TIMSS) over 34 countries. Analysis of international test score data from Machin and Pekkarinen [5] showed a higher variance in boys' than girls' results on mathematics and reading tests in most OECD countries. Higher variability among boys is a salient feature of reading and mathematics test performance across the world.

Thus, the gender difference in mathematics achievement in Australia does not have to be accepted as invariant. However, it is necessary to understand their possible origin to implement strategies which might engage girls and young women in this discipline, and motivate them to pursue studies and careers involving mathematics. One possible cause is a difference in learning style, particularly ways in which individuals interpret the visual environment. Males tend to be more field independent than females [6] with the ability to separate an element from an embedding context [7].

This paper describes a project where information and communication technology (ICT) was used as an integral component of broader curricular reforms [8] by using computer software to teach integral calculus. This highly visual teaching format used visual cues to a high degree, thus creating a delivery tool that possibly suited the learning style of girls.

Although the analysis conducted throughout the project focused on the ability to impart mathematical concepts and practices through ICT, it also enabled a comparison and thus an understanding of the differences between the genders in learning in the primary years, especially in mathematics. It provides an insight into the ability of boys and girls to grasp information pertaining to mathematics based problems when information is provided in various forms, for example the ability of the genders to interpret information presented in graphical form. 


\section{Programme Structure}

The project focused on teaching integral calculus to school pupils aged 10 to 12 years through the use of appropriate computer software and delivery techniques relevant to their experiences. The software selected was MAPLE®, as it is currently used in the first year mathematics units in the Bachelor of Engineering (Maritime) programmes at the University of Tasmania. The intention was for pupils to use the functionality within MAPLE, of which those relevant to the project are summarised below. The software can:

- $\quad$ accept input of mathematical functions;

- manipulate such functions and solve equations algebraically;

- perform calculus operations such as differentiation or integration;

- calculate the value of an integral between given limits; and

- graph and visualize functions and solutions.

For example a plot for the curve $y=x^{2}+3$ produced by a student is shown in Figure 1.

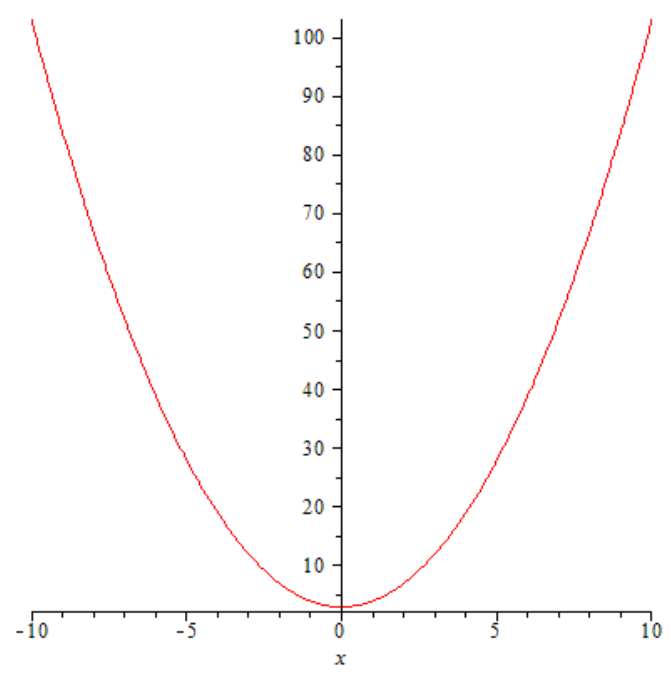

Figure 1. A graphing output using MAPLE

In short, the software removes the need to memorise dozens of integration techniques and accurately calculates the value of a definite integral for a given range. The efficacy of similar software has been demonstrated at undergraduate level, reducing the time to learn calculus by half [9].

The basic methodology was an intervention study involving one class (about 25 students) in four government schools. The latter educate around 66 percent of pupils in Australia [10]. These schools were drawn using purposeful sampling from four separate states, that is Tasmania, Victoria, New South Wales and Queensland, where the targeted pupils had already been assigned individual laptop or netbook computers. Each school provided a designated facilitator to deliver the programme over a 11 week period and manage the assessment component at its culmination.

The programme consisted of 11 one hour periods of intervention instruction by the local facilitator working in tandem with the regular mathematics or class teacher. The delivery was based on a series of simple PowerPoint presentations (as seen in Figure 2) by the facilitator to explain the concepts, followed by an interactive MAPLE worksheet that took the students progressively through a series of examples and exercises, gradually introducing them to new mathematical concepts and MAPLE functions.

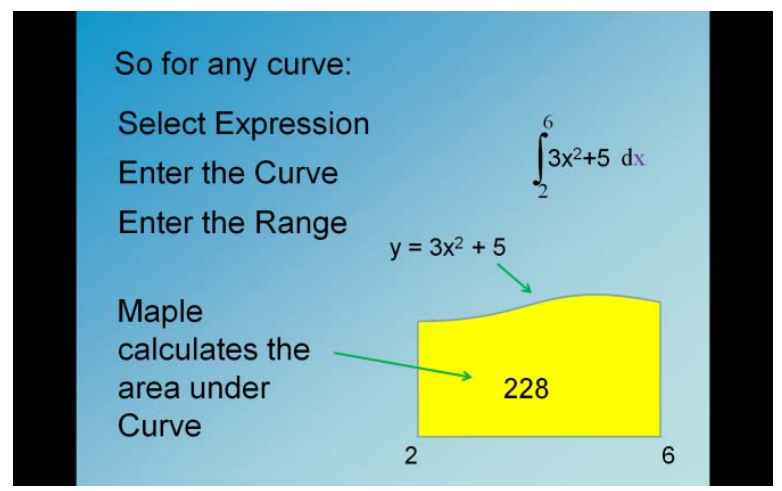

Figure 2. A snapshot of a PowerPoint presentation on how to perform integration

Exercises were first introduced entirely through MAPLE, followed by a number of relevant problems on printed paper (albeit with sketches if required), with an associated MAPLE template to assist with their solution process. The students were allowed to progress through the problem series at their own pace, and encouraged to experiment with the various functions and capabilities of MAPLE.

Recognising that students of this age have short memory spans [11], the programme had inbuilt revision exercises that endeavoured to maintain the competencies acquired during previous sessions. A final assessment of achievement and understanding (another hour, making 12 in total) culminated the intervention and provided data for analysis. In addition to the data gathered from these tests, students and facilitators were interviewed to ascertain their views on the programme and their perceptions on the outcomes.

\section{Methodology}

The first stage was a proof of concept demonstration. There is a general perception among teachers and pupils that integral calculus is one of the more challenging concepts to teach and understand within the school curriculum. Many carry this perception into university, with a number of 
undergraduates finding it difficult to master integral calculus in their first year [12], possibly due to difficulties experienced in school. The reason for the latter possibly stems from their inability to relate the concepts to everyday life, compounded by the difficulty in grasping the associated mathematical manipulations. It was therefore important to identify issues that were relevant to these pupils, thus linking the integration to events and actions that were understood, and importantly seen as 'useful' in their lives. In addition, it ensured that the questions were within their sphere of understanding and skill level.

The approach concept was initially tested on a small number of 11 year old pupils in Launceston, Tasmania. This was considered extremely important for the success of the project as it provided feedback on a number of aspects, including the selection and sequence of topics, relevance and acceptance of the material, ability to comprehend the concepts, and their capability to manipulate the software and its imbedded functions. It was also important to ascertain if the students found the exercise enjoyable and motivating, as the project would inevitably fail if the majority of the students lost interest during the programme. When developing such programmes, it is essential to consider the activities and outcomes from the view point of the target audience, given that most programme designers will have a significantly higher level of mathematics and computer skill.

The next stage consisted of refining the programme and material based on the feedback to meet the skill and interest level of the target student population. This included reorganising the teaching sequence and incorporating real world problems to introduce concepts and activities linked to integral calculus.

Each problem contained a scenario from which a function equation could be derived and an area or rotational volume deduced. It was important pupils saw the relevance of each scenario to their lives, thus catching their interest and providing engagement with the learning of the relevant mathematical concepts. An example problem addresses making a cover for the rain water drain shown in Figure 3. The student is asked to calculate the area in order to obtain sufficient material for it.

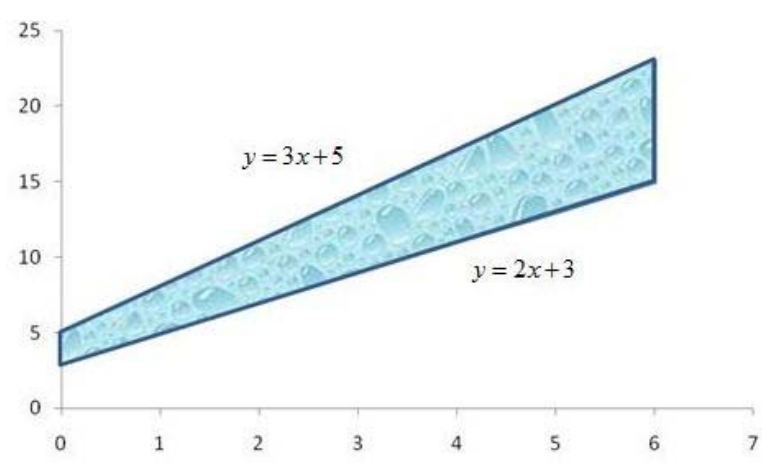

Figure 3. Making a cover for the water drain

Pupils chose the curves as the boundary, and then calculated the integral to find the area to be covered and thus the amount of material required. The problem series were refined in line with the nontemplate problem solving method of Allen [13] and a realistic mathematics education approach [14] with the aid of a teacher advisor to ensure it fits pupils in the targeted age range. Pupils utilised MAPLE (installed on their computer) for algebraic manipulation and calculation of definite integrals, however the problem series ensured they also mastered relevant concepts.

The third stage consisted of recruiting and training the facilitators for each of the four schools to carry out the intervention delivery. Each school was encouraged to recommend a local facilitator, thus ensuring accessibility and acceptance to the students and the school, including meeting all statutory requirements stipulated to those dealing with children. In most cases, the facilitator was the mathematics or class teacher of the students designated for the project.

The research team trained these facilitators through a dedicated one-day training workshop conducted at the University of Tasmania in Launceston aimed at introducing the project goals, mathematical concepts, software (including MAPLE, which was new to all participants), suggested delivery techniques, and the delivery and assessment tools. This included instructional sessions on how to use our problem series and Allen's non-template problem solving method to teach the underlying concepts and their application. For example, the explanations covering the equation of a curve and its integration must be in terms that the pupils can understand and relate to.

The fourth stage was the intervention conducted at the four schools. The facilitators had access to the target classes for two hours per week over six consecutive weeks. During this period, the facilitators gradually introduced each problem, the mathematical concepts, the software tool, and ways to solve the problem using it. For the integral problem dealing with the area of a surface bounded 
by curves (the rain water drain problem in Figure 3), the process was presented as follows. In the first phase the facilitator used the problem to introduce the concepts and solution techniques related to curves and equations. The next phase introduced integration and its solution, including the use of MAPLE to solve the problem. Thus, the facilitators guided the pupils through the solution process, but were also able to ensure they imparted the underlying concepts to the pupils.

During this intervention stage, members of the research team visited each school to ensure that the programme was on track, required outcomes were being met, assist with any difficulties faced by the facilitator, and obtain relevant feedback. An intervention lesson was observed and focus group interviews conducted with pupils where possible. The research team also monitored the progress at each school via telephone conferences and email communication with the facilitators.

In the final stage, the pupils undertook a test based on questions drawn from first year engineering calculus examination papers to assess the knowledge and skills gained through the programme. The questions were provided on a printed sheet of paper, with a MAPLE template for students to carry out the solutions. The latter did not have any of the mathematical material in it, thus the pupils were required to demonstrate their capacity to input mathematical functions through the MAPLE user interface. The completed MAPLE files were collected and analysed by members of the research team. Each participating school was provided with a community report on the project for publication in the local newsletter, and local facilitators given feedback on common mistakes with individual marks and corrected test papers.

\section{Results and Discussions}

The overall aim of this study was to determine the ability to transfer higher level concepts and skills to students using appropriate technology and processes. However, it also provided information on the relationships existing between performance and variables such as gender, school location, and question types. The relevant data for this study were obtained from a total of 89 students of years six and seven from four selected public schools in four states across Australia. A breakdown of the gender over the four states is given in Table 1.
Table 1. Student demographics over four states

\begin{tabular}{|c|c|c|c|c|}
\hline & $\begin{array}{c}\text { VIC } \\
\text { (rural) }\end{array}$ & $\begin{array}{c}\text { TAS } \\
\text { (rural) }\end{array}$ & $\begin{array}{c}\text { QLD } \\
\text { (urban) }\end{array}$ & $\begin{array}{c}\text { NSW } \\
\text { (urban) }\end{array}$ \\
\hline Females & 8 & 12 & 13 & 16 \\
\hline Males & 8 & 11 & 10 & 11 \\
\hline Total & 16 & 23 & 23 & 27 \\
\hline
\end{tabular}

The instrument used for data collection was a test with a total of 13 questions of which five were classed as application questions. These were supplemented by feedback interviews with pupils and facilitators.

The finding of this study showed that students' performance on the test was high. Their performance was similar to that of students in a university engineering course but tested in the traditional way of pen and paper. As described in Fluck, et al [8], the mean scores are above the 50\% required to pass the engineering examination. Students were also able to explain why calculus was useful in the real world. This result indicates that if students have a favourable attitude towards a particular subject, then this will be reflected in their performance in that subject.

The means and standard deviations from the total raw score for each group were compared between the subject factors using the statistical package SPSS. The gender relevant data is summarised in Table 2 . On whether performance is influenced by gender, the preliminary $t$-test assuming equal variances showed no significant difference when comparing the mean scores $(\mathrm{t}$ cal $=1.288<1.663)$. A plot of the cumulative frequency distribution of results illustrated in Figure 4 suggests that there is still a variation in scores at the lower end with females performing better than males. This result is in agreement with Hyde and Mertz [3] that females are now accomplishing as well as males and that the gender gap is closing, possibly due to the methods employed in presenting the material and concepts.

Table 2. Result of t-test analysis of the influence of gender on performance of primary students

\begin{tabular}{|c|c|c|c|c|c|}
\hline Gender & $\boldsymbol{n}$ & Mean & $\begin{array}{c}\text { Standard } \\
\text { deviation }\end{array}$ & $\begin{array}{c}\boldsymbol{t} \text { - } \\
\text { value }\end{array}$ & $\begin{array}{c}\text { Degrees } \\
\text { of } \\
\text { freedom }\end{array}$ \\
\hline Females & 49 & 76.25 & 13.03 & \multirow{2}{*}{$1.288^{*}$} & \multirow{2}{*}{87} \\
\hline Males & 40 & 71.76 & 19.70 & & \\
\hline
\end{tabular}

*Significant at 0.05 level (critical value $\mathrm{t}=1.663$ ) 


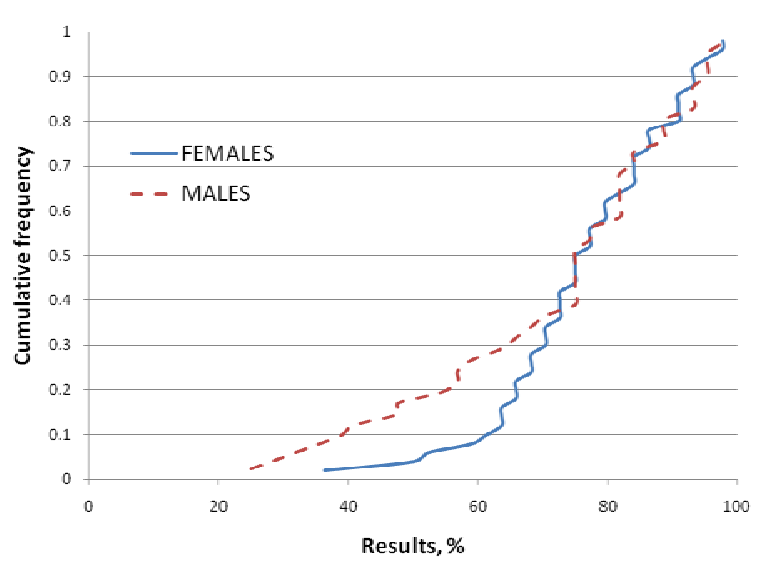

Figure 4. Cumulative Frequency Distribution of results comparing females and males across all states

On whether location of a school influences performance, the preliminary $t$-test showed that students from urban schools performed better than those from rural schools $(\mathrm{t}$ cal $=-4.069<1.663$, see Table 3 and Figure 5). This is possibly due to the schools being better staffed, having better facilities, and the students exposed to good study habits within a conducive learning environment.

Table 3. Result of t-test analysis of the influence of school location on performance of primary students

\begin{tabular}{|c|c|c|c|c|c|}
\hline Location & $\boldsymbol{n}$ & Mean & $\begin{array}{c}\text { Standard } \\
\text { deviation }\end{array}$ & $\begin{array}{c}\boldsymbol{t} \text {-value } \\
\text { Degrees } \\
\text { of } \\
\text { freedom }\end{array}$ \\
\hline Rural & 39 & 66.84 & 17.31 & \multirow{2}{*}{$-4.069 *$} & 87 \\
\hline Urban & 50 & 80 & 13.21 & & \\
\hline
\end{tabular}

*Significant at 0.05 level (critical value $\mathrm{t}=1.663$ )

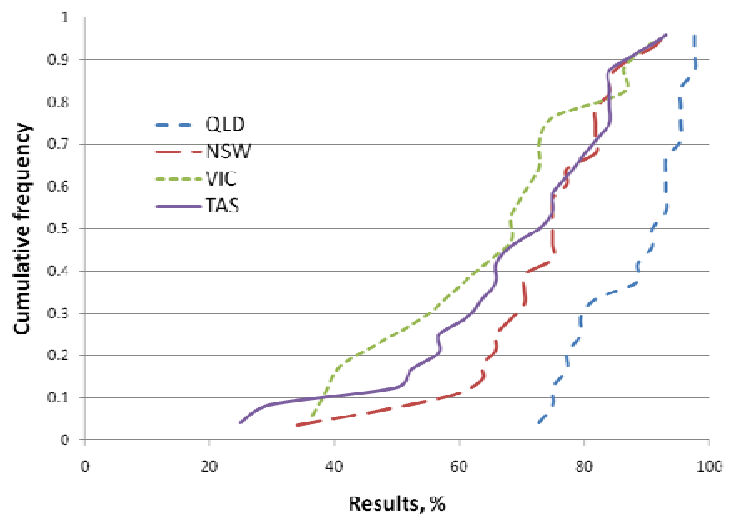

Figure 5. Cumulative Frequency Distribution based on final results
A further analysis on the performance of the individual states (see Figure 5) showed that Queensland students performed significantly higher than those from Victoria, Tasmania and New South Wales, with no significant difference between the latter three states. However, this requires the participation of more schools to provide a definite conclusion.

Table 4. Comparison of the ICSEA across the 4 states

\begin{tabular}{|c|c|c|c|c|}
\hline & $\begin{array}{c}\text { VIC } \\
\text { (rural) }\end{array}$ & $\begin{array}{c}\text { TAS } \\
\text { (rural) }\end{array}$ & $\begin{array}{c}\text { QLD } \\
\text { (urban) }\end{array}$ & $\begin{array}{c}\text { NSW } \\
\text { (urban) }\end{array}$ \\
\hline ICSEA* & 988 & 982 & 1099 & 993 \\
\hline $\begin{array}{c}\text { Mean } \\
\text { Test } \\
\text { Score }\end{array}$ & 64.5 & 65.75 & 82.7 & 63.7 \\
\hline
\end{tabular}

Table 4 shows the Index of Community SocioEducational Advantage (ICSEA) where the mean ICSEA value is 1000 with a standard deviation of 100. Values below the mean indicate schools with fewer advantages. As expected, the mean score of the more advantaged school was higher.

A paired $t$-test of two means with equal variances was used to assess whether students are better at solving real world problems. A plot of the cumulative frequency of results obtained in application questions (shown in Figure 6) showed no significant difference at a 0.05 significance level. Queensland students overall performed better at the application questions with no clear difference between the other three states. However, a $t$-test as illustrated in Table 5 showed that females performed better at solving real world problems than males. This result is contrary to the findings that males tend to be more field independent than females [6, 7]. A further analysis found that when solving non application problems, there was no difference between the gender.

Table 5. Result of t-test analysis of the influence of real world problems on performance of primary students

\begin{tabular}{|c|c|c|c|c|c|}
\hline Gender & $\boldsymbol{n}$ & Mean & $\begin{array}{c}\text { Standard } \\
\text { deviation }\end{array}$ & $\begin{array}{c}\boldsymbol{t}- \\
\text { value }\end{array}$ & $\begin{array}{c}\text { Degrees } \\
\text { of } \\
\text { freedom }\end{array}$ \\
\hline Females & 49 & 76.84 & 16.76 & $2.012^{*}$ & 87 \\
\hline Males & 40 & 67.13 & 28.26 & & \\
\hline
\end{tabular}

*Significant at 0.05 level (critical value $\mathrm{t}=1.663$ ) 


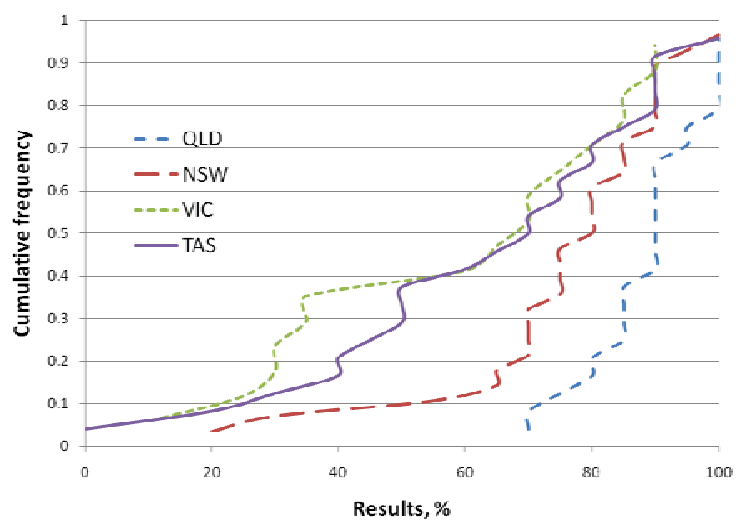

Figure 6. Cumulative Frequency Distribution of performance in application questions

To pass the test, a student must obtain $50 \%$ or above. Only 13 of the 89 pupils scored below this level. Of these, 9 were males. Not surprisingly, the school with the highest ICSEA did not record a failure.

Table 6. Percentage of class obtaining $80 \%$ and above

\begin{tabular}{|c|c|c|c|c|}
\hline & $\begin{array}{c}\text { VIC } \\
\text { (rural) }\end{array}$ & $\begin{array}{c}\text { TAS } \\
\text { (rural) }\end{array}$ & $\begin{array}{c}\text { QLD } \\
\text { (urban) }\end{array}$ & $\begin{array}{c}\text { NSW } \\
\text { (urban) }\end{array}$ \\
\hline Females & 18.75 & 16.7 & 30.4 & 10.7 \\
\hline Males & 0 & 16.7 & 26.1 & 7.1 \\
\hline
\end{tabular}

Table 6 shows the percentage of the class obtaining $80 \%$ and above in the test, equivalent to a high distinction grade in university. It is clear that females performed stronger. Again, the school with the highest ICSEA performed best overall.

In addition to the quantitative results we also examined the interviews with pupils and their responses to the question "What is calculus good for?" on the test paper. Pupils at the NSW school showed a good understanding of calculus, stating it was useful:

- To work out maths for work or school. It can be used for working out how many kilometers to somewhere or to measure a garden.

- Because it helps you measure and calculate the distance and area of places. eg. how far you throw a ball. ... thank you...

- It is useful because you can go home and do calculus. Went [sic] you start it looks hard.

These pupils used 15” screen Acer and Dell laptops financed by the school and by parents and shared their work at home. They celebrated their learning because they were able "to outwit Mum \& Dad" or more seriously, "measure my house - figure out how much building material went into it". They enjoyed graphing functions.
The QLD school pupils showed a good understanding of calculus, stating it was useful because:

- It helps us work out real life shapes and equations. You can work out the area of a swimming pool or a skateboard ramp.

- It is helpful because you can use it in real life situations. It is a good software and lets kids know what you will be using if you become an engineer. If someone knows how to work with all the expressions and what they mean, MAPLE 13 can be really easy.

One girl said "My dad's an architect, so I showed him MAPLE. He had a go with it. He said he wished he'd had it when he was studying! My mum doesn't like it because she doesn't understand it. And she's a teacher at this school!" These comments are particularly important, because they epitomise the gulf between school-based learning and functional professional use of these important mental tools. The teacher from QLD took the program further and taught students to design drinking cups and beakers using the software (see Figure 7).

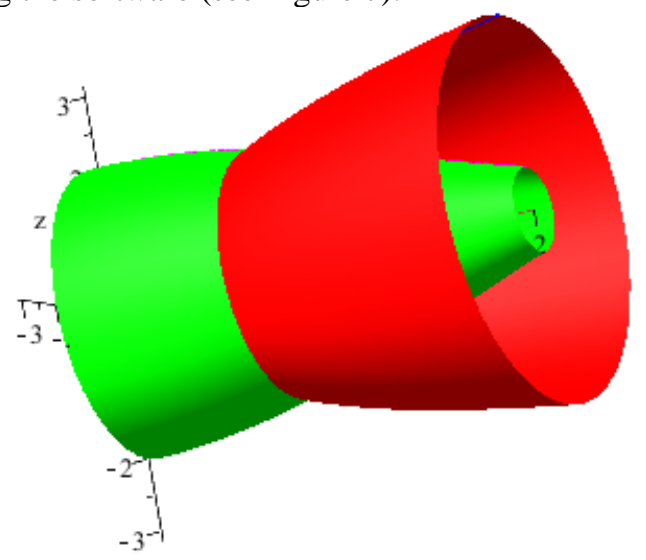

Figure 7. Beaker designed by a pupil using MAPLE software

Pupils at the VIC school stated Calculus was useful because:

- It can help measure things that are curved. It can also be used to measure things that are on different angles on different areas. It can be useful for example to find out how much cement you need to make a skate ramp.

- I find Maple fun to learn and I would recommend it to all the schools. P.S. It's a good way to get out of maths!!

- It made maths a lot more fun and easy. I wish we could use it all the time!

These pupils used netbooks provided by the school and were able to bring their netbooks home and shared what they have been doing with their friends and family. Pupils said the calculus software would be useful at work (e.g. for a builder to know how much cement they need) and for homework. A 
few had used MAPLE to do their other homework and saw the potential of using it for other studies (especially homework) and applications. Students had found new mathematical functions on their own and most felt they had learnt new things through the project, such as cubic equations and graph plotting.

Pupils at the TAS school showed a good understanding of calculus, stating it was useful:

- To work out the area of a building.

- It can help you figure out difficult questions easily.

- Because if you're painting a house or a skate ramp it tells you how much paint or whatever it is you need to get. It can save you money and time.

- $\quad$ Because some of the questions look difficult but if you use this, it is really easy.

These pupils used Lenovo netbooks provided by the school. Pupils took their netbooks home and shared what they have been doing. Some had shown it to friends, and seven had shown it to parents; four of whom had been impressed. Pupils said the calculus software would be useful at work (e.g. for an electrician) and for homework.

In the marking of the tests, common mistakes were noted and were summarised in a community report distributed to the schools. One of the common mistakes that students made when computing $\int_{0}^{2} \frac{2 x+1}{(x-1)(x-3)} d x$ in MAPLE is that pupils omitted a multiplication sign when typing the product of the two functions $(x-1)$ and $(x-3)$. This caused a significant number of students to output the wrong integral and hence answers. An example has since been included in a worksheet to reflect the importance of the multiplication sign. Another common mistake is the mixed use of upper and lower cases. MAPLE regards the upper and lower case of the same letter as 2 different variables. This resulted in incorrect results. Forgetting to change the variable from $d x$ to $d t$ when integrating a $t$-dependent function resulted in incorrect answers.

\section{Conclusions}

The results described in this study have made it possible to analyse and thus understand some of the factors that influence the performance of students aged between 10 and 12 years in the learning of mathematics related material. The project has demonstrated successful curriculum transformation through the use of ICT by showing that 10 year old students in school can learn integral calculus through the use of appropriate technology and techniques. The results indicate that the students have acquired a good understanding of the concepts and the relevant applications. The interview and qualitative responses show the pupils had a good understanding of what they were doing. It must be clear that since they used a computer for the final test, their capacity to 'do calculus' is unconventional, and this perhaps provokes us to consider what is meant by the term. It is our feeling that they demonstrated a capacity to understand and use integral calculus in a way which professional engineers would do so - as a tool to accomplish a goal.

Across all four states tested, Queensland outperformed the other three states, although this needs further data to be verified, while students from urban schools performed better than those from rural schools. Overall, across all states, females performed better than their male counterparts, with a distinct difference in their ability to solve real world problems. These results clearly indicate a favourable attitude and interest towards the subject, with the techniques employed able to stimulate the interest of the female students. The study also showed that students from the more advantaged school performed better than the others.

The paper evaluates some influential factors such as school location and gender, but leaves others such as age and school type (private versus public schools) requiring the collection of further data. Hence, it is intended to expand the project to additional schools across Australia and New Zealand, thus addressing these variables and increasing the sample population. A current extension to the project is trialling the MAPLE software in a school within a low-socio-economic background area, using laboratory-based computers. This more accurately represents the situation in Australian government schools because the Digital Education Revolution policy only provides individual computer access for older pupils in Years 9-12. In addition, the research team plans to employ some open-source software that has similar functionality to MAPLE but a more unconventional interface, where the student has to learn types of inline linear syntax and code to input expressions. This may prove to be more difficult and have an influence on the learning of the student and their overall performance. One suggestion is that pupils may progress using conventional mathematical notation on paper, but use the textual input method in parallel to obtain calculated results from the computer. This has the advantage that pupils will become familiar with hand-writing conventional notation, but the disadvantage of introducing a cross-coding complication into the learning process.

The professions that require mathematical knowledge extend far beyond engineering and the sciences. Furthermore, successful application of mathematics today requires new conceptual understanding, and computational skills that capitalise on the availability of tools such as graphing and computer algebra systems. It is therefore important that we understand and utilise 
these techniques to inspire students to take up and enjoy the learning of mathematics related content.

\section{References}

[1] Edwards, D. and Smith, T. F. "Supply, demand and approaches to employment by people with postgraduate research qualifications in science and mathematics” pp. 50 Available at:

http://www.dest.gov.au/NR/rdonlyres/DBB14069-3A4744A0-8945-

3BC55D6E23D4/25788/SciandMathPGsLitRevandDataAn alyisFINALARFeb09.pdf (Access date: 1 December 2010)

[2] Hyde, J.S., Lindberg, S.M., Linn, M.C., Ellis, A.B. and Williams, C.C., "Gender Similarities Characterize Math Performance", American Association for the Advancement of Science, USA, 25 July 2008, Vol. 321, pp 494-495.

[3] Hyde, J.S. and Mertz, J.E., "Gender, culture, and mathematics performance", Proceedings of the National Academy of Sciences of the United States of America, USA, June 2 2009, Vol. 106, No. 22, pp. 8801-8807.

[4] Nosek, B.A., Smyth, F.L., Sriram, N., Lindner, N.M., Devos, T., Ayala, A., Bar-Anan, Y., Bergh, R., Cai, H., Gonsalkorale, K., Kesebir, S., Maliszewski, N., Neto, F., Olli, E., Park, J., Schnabel, K., Shiomura, K., Tulbure, B.T., Wiers, R.W., Somogyi, M., Akarami, N., Ekehammar, B., Vianello, M., Banaji, M. and Greenwald, A.G., "National differences in gender - science stereotypes predict national sex differences in science and math achievement”, Proceedings of the National Academy of Sciences of the United States of America, USA, June 30 2009, Vol. 106, No. 26, pp. 10593-10597.

[5] Machin, S. and Pekkarinen, T., "Global Sex Differences in Test Score Variability", American Association for the Advancement of Science, USA, 28 November 2008, Vol. 322, pp 1331-1332.

[6] Witkin, H.A., Moore, C.A., Goodenough, D.R., and Cox, P.W., Field dependent and field independent cognitive styles and their educational implications, Review of Educational Research, 1977, 47(1), 1-64.

[7] Bosacki, S., Innerd, W. and Towson, S., Field Independence-Dependence and Self-Esteem in Preadolescents: Does Gender Make a Difference?, Journal of Youth and Adolescence, Plenum Publishing Corporation, Vol. 26, No. 6, 1997, pp. 691-703.

[8] Fluck, A.; Ranmuthugala, D.; Chin, CKH. and Penesis, I. (2011) Calculus in elementary school: an example of ICT-based curriculum transformation. In Proceedings of Society for Information Technology \& Teacher Education International Conference 2011 (pp. 3203-3210). Chesapeake, VA: AACE. Retrieved from http://www.editlib.org/p/36810

[9] Palmiter, J. R. (1991) "Effects of Computer Algebra Systems on Concept and Skill Acquisition in Calculus", Journal for Research in Mathematics Education 22 (2), 1991, pp. 151-156.
[10] Australian Bureau of Statistics (2009). Schools Australia 4221.0. Canberra, Available at http://www.ausstats.abs.gov.au/ausstats/subscriber.nsf/0/05 ADAC0812C70C9DCA25775700218CA4/\$File/42210_20 09.pdf (Access date: 17 October 2010)

[11] Cestari, V., Lucidi, A., Pieroni, L and Rossi-Arnaud Clelia, "Memory for Object Location: A Span Study in Children", The Cognitive Science Journal, pp. 408-411, 2005.

[12] Galbraith, P. and Haines, C. "Conceptual mis(understandings) of beginning undergraduates", International Journal of Mathematical Education in Science and Technology, 31, 2000, pp. 651-678.

[13] Allen, D. "Learning integral calculus through nontemplate problem solving", Primus: Problems, Resources, and Issues in Mathematics Undergraduate Studies 11(2), 2001, pp. 147-160.

[14] Gravemeijer, K. and Doorman, M., "Context problems in realistic mathematics education: a calculus course as an example”, Educational Studies in Mathematics 39, 1999, pp.111-129. 